Weed Science 2018 66:180-189

(C) Weed Science Society of America, 2017. This is an Open Access article, distributed under the terms of the Creative Commons Attribution-NonCommercial-ShareAlike licence (http://creativecommons. org/licenses/by-ncsa/4.0/), which permits non-commercial re-use, distribution, and reproduction in any medium, provided the same Creative Commons licence is included and the original work is properly cited. The written permission of Cambridge University Press must be obtained for commercial re-use.

\title{
Evolutionary Adaptations of Palmer Amaranth (Amaranthus palmeri) to Nitrogen Fertilization and Crop Rotation History Affect Morphology and Nutrient-Use Efficiency
}

\author{
Washington Bravo, Ramon G. Leon, Jason A. Ferrell, Michael J. Mulvaney, and C. Wesley Wood*
}

Palmer amaranth control has become a major challenge for multiple cropping systems across the southeastern and midwestern United States. Despite extensive research on herbicide-resistance evolution, little research has been done exploring how Palmer amaranth might also be evolving other adaptive traits in response to different selection forces present in agricultural fields and the enrichment of soils with nutrients such as nitrogen. The objective of the present study was to determine whether Palmer amaranth populations have evolved different morphology and growth patterns in response to glyphosate use and fertilization history. Ten Palmer amaranth populations, including glyphosate-resistant (GR) and glyphosate-susceptible (GS) populations, were collected from different cropping systems with histories of high and low nitrogen fertilization in the states of Florida and Georgia. All populations were grown in pots filled with soil fertilized with either 0 or $40 \mathrm{~kg} \mathrm{Nha}^{-1}$, and their response to nitrogen was compared for morphological, growth, and nutrient-use traits. Populations differed in how they modified their morphology and growth in response to $\mathrm{N}$, with major differences in traits such as foliar area, branch production, leaf shape, and canopy architecture. Populations with high nitrogen-fertilization histories had higher (>43\%) nutrient-use efficiency (NUE) than populations with low nitrogen-fertilization histories. Similarly, GR populations have evolved higher NUE $(>47 \%)$ and changed canopy architecture more than GS populations in response to nitrogen fertilization. The results of the present study highlight the importance of paying more attention to adaptations to cultural practices that might increase weediness and how genetic changes in traits involved in morphology and metabolism might favor compensatory mechanisms increasing the fitness of the population carrying herbicide-resistant traits.

Nomenclature: Glyphosate; Palmer amaranth, Amaranthus palmeri S. Wats. AMAPA.

Key words: Crop rotation, evolution, fitness, integrated weed management, nutrient content, resistance.

Palmer amaranth, a dioecious weed species native to the southwestern desert region of the United States, has been listed as one of the most troublesome weed species with rapid expansion throughout the midwestern and southern regions of the United States (Butts et al. 2016; Webster and Coble 1997). Abundant seed production and high interference potential make this weed species a serious threat to crop production (Webster and Coble 1997; Wiggins et al. 2015). Most non-legume agronomic crops will regularly receive nitrogen fertilization to maximize

DOI: $10.1017 /$ wsc.2017.73

* First and third authors: Graduate Student and Professor, Agronomy Department, University of Florida, Gainesville, FL 32611; second author: Assistant Professor, Department of Crop and Soil Sciences, North Carolina State University, Raleigh, NC 27695; fourth and fifth authors: Assistant Professor and Professor, West Florida Research and Education Center, University of Florida, Jay, FL 32565. Corresponding author’s E-mail: rleon@ncsu.edu yield. However, many studies have also shown that weed species take advantage of crop nitrogen fertilization by physiologically increasing seed production, germination rate, growth rate, and biomass partitioning (Sweeney et al. 2008; Wortman et al. 2011). This is especially important in Palmer amaranth; previous studies have reported it as a species that is highly responsive to nitrogen fertilization (Ruf-Pachta et al. 2013).

The control of Palmer amaranth populations has become a challenge due to the evolution of resistance to different herbicides, including triazine, acetolactate synthase (ALS) inhibitors, dinitroaniline, hydroxyphenylpyruvate dioxygenase inhibitors, and protoporphyrinogen oxidase-inhibiting herbicides, during the last two decades (Gaeddert et al. 1997; Gossett et al. 1992; Heap 2017; Jhala et al. 2014; Ward et al. 2013). Palmer amaranth has also evolved resistance to glyphosate, the most widely used herbicide in 
agronomic crops in the United States. Although the first report of glyphosate-resistant (GR) Palmer amaranth originated in the state of Georgia (Culpepper et al. 2006), since 2008 there have been confirmed cases of GR populations in Alabama, Arkansas, Florida, Mississippi, Missouri, New Mexico, North Carolina, South Carolina, and Tennessee (Berger et al. 2015; Heap 2017; MohseniMoghadam et al. 2013; Norsworthy et al. 2008).

Because of its dioecious reproductive system, Palmer amaranth has high genetic variability, which is predominantly found within populations and to a lesser extent among populations (Chandi et al. 2013b). In other words, differentiation among populations (measured with neutral molecular markers) seems to be low due to gene flow, but individuals within populations have marked differences in their genetic makeup. However, because selection forces in agricultural fields are considerably high, it is possible that key life-history traits might be under selection. If this selection increases weed survival, populations could eventually differentiate for these traits despite the high levels of gene flow. Ignoring such differentiation processes can result in increased weediness.

Bravo et al. (2017) reported differentiation of several life-history traits among 10 Palmer amaranth populations, and the differences seem to be related to particular characteristics of the cropping systems where the populations were found. Moreover, it was reported that GR populations produced more biomass and were taller than glyphosate-susceptible (GS) populations, although previous reports found no differences in fitness between GR and GS Palmer amaranth populations (Giacomini et al. 2014; Vila-Aiub et al. 2014).

Considering that Palmer amaranth was adapted to low nitrogen availability, as a native species from desert regions (Ward et al. 2013), and that this weed is successfully colonizing agricultural systems with high nitrogen-fertilization inputs, we proposed that Palmer amaranth populations have evolved to take advantage of nitrogen fertilization to increase their growth and competitive ability within crops. Also, we proposed that adaptations to nitrogen fertilization might be related to growth differences between GR and GS populations (Bravo et al. 2017). Therefore, we tested two hypotheses: (1) Palmer amaranth populations originating from cropping systems with high nitrogen-fertilization histories will modify growth more in response to nitrogen fertilization than populations from systems with low nitrogen-fertilization histories, and (2) GR Palmer amaranth populations have higher nitrogen-use efficiency than GS populations. This information is critical to assess how cultural practices not only affect Palmer amaranth success in agricultural fields but also influence GR population dynamics.

\section{Materials and Methods}

Seed Collection. The present study used the same Palmer amaranth populations reported by Bravo et al. (2017). Seeds from 10 populations of Palmer amaranth were collected in Florida and Georgia during the fall 2014 in coordination with local growers and county extension agents who had previously identified fields with a history of issues with this weed species. Field agricultural management history was considered in selecting sampling locations. Factors such as glyphosate sensitivity (determined by Bravo et al. 2017 with dose-response studies), nitrogen-fertilization history, crop rotation, and crop canopy structure were the main selection

Table 1. Origin and crop history of 10 Palmer amaranth populations.

\begin{tabular}{lllll}
\hline State & County & Crop rotation & $\begin{array}{l}\text { Nitrogen-fertilization } \\
\text { history }\end{array}$ & Abbreviation \\
\hline Florida & Jackson & Peanut-maize-soybean & High & P1-RH \\
& Jackson & Peanut-cotton & High & P2-RH \\
& Jackson & Maize-peanut & Low & P3-RL \\
& Levy & Peanut-peanut & Low & P4-SL \\
& Levy & Peanut-peanut & High & P5-SL \\
Georgia & Tift & Peanut-cotton & High & P7-RH \\
& Macon & Soybean-cotton & Low & P8-RL \\
& Sumter & Soybean-winter wheat & High & P9-SH \\
& Bulloch & Organic vegetables-sweet maize & P10-SH \\
\hline
\end{tabular}

\footnotetext{
${ }^{a}$ Populations were classified as high $(\mathrm{H})$ and low $(\mathrm{L})$ according to nitrogen-fertilization history, with high and low receiving an average over $8 \mathrm{yr}$ of $>90$ and $<45 \mathrm{~kg} \mathrm{Nha}^{-1} \mathrm{yr}^{-1}$, respectively. Populations were also classified as glyphosate resistant (R) and susceptible (S) based on Bravo et al. (2017).
} 
criteria (Table 1). At every location, Palmer amaranth seeds were collected from plants found inside the crop in the first $25 \mathrm{~m}$ from field borders. Seeds were collected from 8 female plants (i.e., seeds from a single female plant were considered a family) within a $3-\mathrm{m}$ radius in heavily infested areas (i.e., 0.5 to 15 females $\mathrm{m}^{-2}$ ), and sampling locations were at least $2.5 \mathrm{~km}$ apart. Once collected, the seeds were labeled and kept separated in paper bags until the initiation of the experiment.

Outdoor Pot Experiment. Outdoor pot experiments were conducted in the spring-summer season of 2015 at the West Florida Research and Education Center in Jay, FL. Palmer amaranth seeds were germinated on trays under greenhouse conditions. Once plants reached the 3-leaf stage, a single plant was transplanted into 10.7-L pots filled with the Ap horizon of a Red Bay sandy loam soil (Fine-loamy, kaolinitic, thermic Rhodic Kandiudult) containing $3.6 \mathrm{mg} \mathrm{N} \mathrm{kg}^{-1}, 1.6 \%$ organic matter, $69 \%$ sand, $16 \%$ silt, and $15 \%$ clay with $\mathrm{pH} 6$ from the West Florida Research and Education Center in Jay, FL, and placed outdoors. Plants were watered on a daily basis with a drip-irrigation system to maintain soil field capacity. Although the soil did not have a natural Palmer amaranth seedbank, hand weeding was conducted as needed to avoid interference from other weed species. The experiment was arranged as a completely randomized design with six replications per treatment. Treatments were combinations of 10 populations and 2 fertilization treatments: 0 and $40 \mathrm{~kg} \mathrm{~N} \mathrm{ha}^{-1}$ (i.e., 0 and $1.3 \mathrm{~g} \mathrm{~N}_{\text {pot }}{ }^{-1}$, respectively, based on pot area), and the experiment was conducted twice. This fertilization rate was chosen after conducting preliminary studies. This amount of fertilizer allowed clear detection of fertilization responses without causing root or leaf burning due to overfertilization. The first experiment was initiated in late April and the second one in early June. Families were used as replications, so we could capture intrapopulation variability, but due to limited space, only six families were randomly selected from the eight families collected per population in the field. Ammonium nitrate was used as nitrogen source and was applied by burying it at $3 \mathrm{~cm} 7 \mathrm{~d}$ after transplanting.

Palmer amaranth response to nitrogen availability was evaluated when plants reached anthesis. At this point, multiple traits involved in plant architecture, growth rate, and nutrient-use efficiency (NUE) were measured to compare populations. These traits were chosen because they can influence crop interference, light interception, photosynthetic rate, and reproductive success. Traits included number of days to anthesis and greenness (Wood et al. 1992) for each plant, averaging SPAD 502 Plus Chlorophyll Meter (Spectrum Technologies, Lincoln, NE) readings made on the 2nd, 3rd, and 4th fully developed leaves. Furthermore, to explore allometric variation in leaf and canopy morphology, the 2nd and 3rd fully developed leaves were measured for petiole and leaf-blade length. Also, leaf-blade width was measured at three equidistant points (i.e., tip, middle, base); the same approach was followed to determine canopy shape. Thus, plant height was measured, and then the canopy was divided into three sections along the main stem, and canopy width was determined at the top, middle, and base of the plant. After these evaluations, plants were clipped at soil level, and their fresh weight was determined. The apical inflorescence was clipped, and its length and weight were measured. Similarly, axillary inflorescences were removed from the plant, dried, and weighed separately. All leaves were clipped and counted, and total leaf area was determined with a LI-3100 Area Meter (Li-Cor Biosciences, Lincoln, NE).

Fresh weight of aboveground biomass was determined, and plants were dried, weighed, and ground. Total ground-tissue samples were sent to the University of Florida Institute of Food and Agricultural Sciences Analytical Services Laboratories (Gainesville, FL) for nutrient content determination. The estimation of total nitrogen in shoot tissue was performed using total Kjehldahl nitrogen (EPA 1993), and total phosphorus, potassium, magnesium, and zinc content was determined following the ICP emission spectroscopy methodology (EPA 1994).

Data Analysis. Because Bravo et al. (2017) already demonstrated differences in growth and morphology among the studied Palmer amaranth populations, the analysis of the present study was focused on changes in growth as a result of nitrogen fertilization. For this reason, all traits were converted to a relative response to nitrogen based on the values observed for nonfertilized plants. Therefore, responses of $1,<1$, and $>1$ indicate no change, reduction, and increase under fertilized conditions compared with the nonfertilized control, respectively. Additionally, we quantified tissue content for several nutrients and estimated NUE (Cassman et al. 1998; De Datta and Broadbent 1988):

$$
\mathrm{NUE}=\mathrm{DW} / \mathrm{N}
$$

were DW represents dry weight $(\mathrm{g})$, and $\mathrm{N}$ is nutrient content (mg). 
The data were analyzed separately in four different (i.e., separate) ways: by sex (female vs. male); by population, by glyphosate sensitivity, and by nitrogen-fertilization history. For glyphosate sensitivity, populations were grouped as GR and GS as reported by Bravo et al. (2017). Also, populations were grouped based on nitrogenfertilization history. Populations were classified as high nitrogen history if they received more than $90 \mathrm{~kg} \mathrm{Nha}^{-1} \mathrm{yr}^{-1}$ from fertilizers during the Palmer amaranth growing season and as low-nitrogen history if they received less than $45 \mathrm{~kg} \mathrm{Nha}^{-1} \mathrm{yr}^{-1}$ from fertilizers during the last $8 \mathrm{yr}$. The results were subjected to ANOVA $(\alpha=0.05)$ using R (R Core Team 2014). Normality and homoscedasticity assumptions were checked using Q-Q plot and plotting the residuals versus predicted values. Data were square-root transformed for number of branches from main stem, 3rd leaf-tip width, and the ratio of the traits evaluated for the 2 nd and 3 rd leaves when needed to meet ANOVA assumptions, but nontransformed means are shown in the results. ANOVA models included treatment, experimental run, and their interaction as fixed effects. Mean separation was done using Tukey's honestly significant difference (HSD; $\alpha=0.05$ ). Nutrient content and NUE were evaluated using absolute values, including the fertilized and nonfertilized treatments, so the aforementioned ANOVAs also included the nitrogen-fertilization treatment effect and its interaction with the other factors. One-tailed $t$-tests $(\alpha=0.05)$ were used to compare different growth, morphology, nutrient content, and NUE between GR versus GS and high- versus lownitrogen history populations after confirming the absence of significant interactions between experimental factors.

\section{Results and Discussion}

No interactions were detected among experimental runs and other effects (i.e., population, nitrogen-fertilization history, glyphosate sensitivity) in the ANOVA model ( $\mathrm{P} \geq 0.73)$; consequently, data were pooled over the two experimental runs. Additionally, all populations and treatments had a 1:1 ratio of female:male plants, and no differences due to sex were observed for the different parameters $(P>0.42)$. Therefore, further analyses were conducted pooling data from female and male plants.

Multiple life-history traits changed among populations in response to nitrogen fertilization $(\mathrm{P}<0.01)$. Traits such as plant height, foliar area, number of branches from the main stem, the 3rd leaf-tip and leaf-base widths, SPAD values, and allometric ratios of the 3rd leaf and canopy architecture exhibited significant differences among populations (Table 2). Overall, no single population exhibited an increase in all traits in response to nitrogen fertilization, so changes depended on specific trait and population combinations (Table 3). Branch number was the morphological trait that varied the most in response to nitrogen fertilization. For example, P7-RH had a 6-fold increment in branch number compared with other populations such as $\mathrm{P} 10-\mathrm{SH}$, which had almost no change in branch number after nitrogen fertilization (Table 3). This increment in production of branches as a response to nitrogen fertilization could be advantageous when competing with a crop.

No changes in dry weight in response to the nitrogen fertilization were detected, but differences for height, foliar area, number of branches, and SPAD values varied depending on the nitrogen-fertilization histories of the cropping systems (Table 2). Populations with low nitrogen-fertilization histories were $30 \%$ taller than populations with high nitrogenfertilization histories, but the foliar area was 30\% higher for high-nitrogen populations in response to nitrogen fertilization than low-nitrogen populations (Figure 1). Populations with high nitrogenfertilization histories increased branch number $85 \%$ and SPAD values $9 \%$ more than populations with low nitrogen-fertilization histories. The capacity of Palmer amaranth to take advantage of the extra nitrogen provided by fertilizers can be associated to its nitrophilous nature, previously reported by Ward et al. (2013) and Ruf-Pachta et al. (2013).

When populations were grouped based on glyphosate sensitivity, several differences in the response to nitrogen fertilization were detected for morphological traits. GR populations tended to have a wider base on the 3rd leaf, and the leaf blade was larger with respect to the petiole than GS populations (Figure 2). Furthermore, GR populations exhibited a 36\% more-elongated canopy architecture than GS populations, and the latter presented a canopy $16 \%$ wider in the middle compared with the former (Figure 2).

Considering these results, we investigated whether differences in morphology and growth might be related to differences in nutrient use, since changes in dry weight in response to nitrogen fertilization were not different among populations (Table 2).

No interactions between nitrogen-fertilization treatments and populations were observed for NUE $(\mathrm{P}>0.15)$, so data from fertilized and 
Table 2. ANOVA statistical significance of morphological and growth traits in response to nitrogen fertilization comparing 10 Palmer amaranth populations grouped by glyphosate sensitivity (resistant vs. susceptible) and by nitrogen-fertilization history (high vs. low).

\begin{tabular}{|c|c|c|c|}
\hline Traits & Populations & $\begin{array}{l}\text { Glyphosate } \\
\text { sensitivity }^{\mathrm{a}}\end{array}$ & $\begin{array}{c}\text { Nitrogen-fertilization } \\
\text { history }^{\mathrm{b}}\end{array}$ \\
\hline & \multicolumn{3}{|c|}{-P value- } \\
\hline Days to flowering & 0.17 & 0.51 & 0.60 \\
\hline Height & 0.05 & 0.54 & $<0.01$ \\
\hline Fresh weight & 0.35 & 0.87 & 0.13 \\
\hline Dry weight & 0.13 & 0.76 & 0.69 \\
\hline Inflorescence weight & 0.07 & 0.28 & 0.54 \\
\hline Inflorescence length & 0.67 & 0.94 & 0.17 \\
\hline Axillary inflorescence weight & 0.33 & 0.15 & 0.48 \\
\hline Foliar area & $<0.01$ & 0.3 & 0.02 \\
\hline Number of leaves & 0.77 & 0.93 & 0.11 \\
\hline No. axial leaves & 0.24 & 0.29 & 0.07 \\
\hline No. branches from main stem & $<0.01$ & 0.06 & $<0.01$ \\
\hline 2nd leaf-blade length & 0.24 & 0.54 & 0.33 \\
\hline 3rd leaf-blade length & 0.19 & 0.22 & 0.32 \\
\hline 2nd leaf-petiole length & 0.21 & 0.58 & 0.69 \\
\hline 3rd leaf-petiole length & 0.07 & 0.06 & 0.95 \\
\hline 2nd leaf-tip width & 0.33 & 0.16 & 0.80 \\
\hline 2nd leaf-middle width & 0.13 & 0.67 & 0.29 \\
\hline 2nd leaf-base width & 0.27 & 0.89 & 0.66 \\
\hline 3rd leaf-tip width & $<0.01$ & 0.41 & 0.34 \\
\hline 3rd leaf-middle width & 0.15 & 0.09 & 0.34 \\
\hline 3rd leaf-base width & 0.04 & 0.02 & 0.59 \\
\hline Diameter of canopy top & 0.52 & 0.44 & 0.93 \\
\hline Diameter of canopy middle & 0.12 & 0.01 & 0.87 \\
\hline Diameter of canopy base & 0.01 & 0.15 & 0.89 \\
\hline SPAD & $<0.01$ & 0.32 & 0.01 \\
\hline Ratio 2nd leaf-tip width/leaf length & 0.39 & 0.12 & 0.18 \\
\hline Ratio 2nd leaf-middle width/leaf length & 0.47 & 0.78 & 0.78 \\
\hline Ratio 2nd leaf-base width/leaf length & 0.12 & 0.79 & 0.68 \\
\hline Ratio 2nd leaf length/petiole length & 0.98 & 0.94 & 0.83 \\
\hline Ratio 3rd leaf-tip width/leaf length & 0.01 & 0.14 & 0.73 \\
\hline Ratio 3rd leaf-middle width/leaf length & 0.5 & 0.71 & 0.62 \\
\hline Ratio 3rd leaf-base width/leaf length & $<0.01$ & 0.26 & 0.14 \\
\hline Ratio 3rd leaf-length/petiole length & $<0.01$ & $<0.01$ & 0.47 \\
\hline Ratio canopy-top width/canopy height & 0.43 & 0.48 & 0.37 \\
\hline Ratio canopy-middle width/canopy height & $<0.01$ & 0.04 & 0.02 \\
\hline Ratio canopy-base width/canopy height & $<0.01$ & 0.23 & 0.07 \\
\hline
\end{tabular}

${ }^{\text {a }}$ Four populations were identified as susceptible $(n=48)$ and six as resistant $(n=72)$ to glyphosate.

${ }^{\mathrm{b}} \mathrm{Six}$ populations were identified as high $(n=72)$ and four as low $(n=48)$ nitrogen-fertilization history.

nonfertilized plants were pooled when comparing populations and groups based on glyphosate sensitivity and nitrogen-fertilization history. Palmer amaranth populations had a few differences in nutrient content $(0.008 \leq \mathrm{P} \leq 0.31)$, but there were clear differences in NUE $(\mathrm{P} \leq 0.007$; Table 4).

Similar to the response observed for morphology, high variation was observed among populations for nutrient content and NUE, but no trend was observed among populations, and only a few populations differed based on Tukey's HSD (Table 5).
No differences in nutrient content were observed when comparing populations with different nitrogenfertilization histories $(P>0.12)$, but clear differences in NUE were found between populations with high and low nitrogen-input histories (Table 6). In general, populations with high nitrogen-fertilization histories exhibited $43 \%$ to $59 \%$ higher NUE than populations with low nitrogen-fertilization histories, depending on the nutrient. Also, GR populations had at least $47 \%$ higher relative NUE than GS populations (Table 7). The differences in NUE were partially explained by GR populations 
Table 3. Relative change in morphological and growth traits in response to nitrogen fertilization among 10 Palmer amaranth populations based on a nonfertilized control. ${ }^{a}$

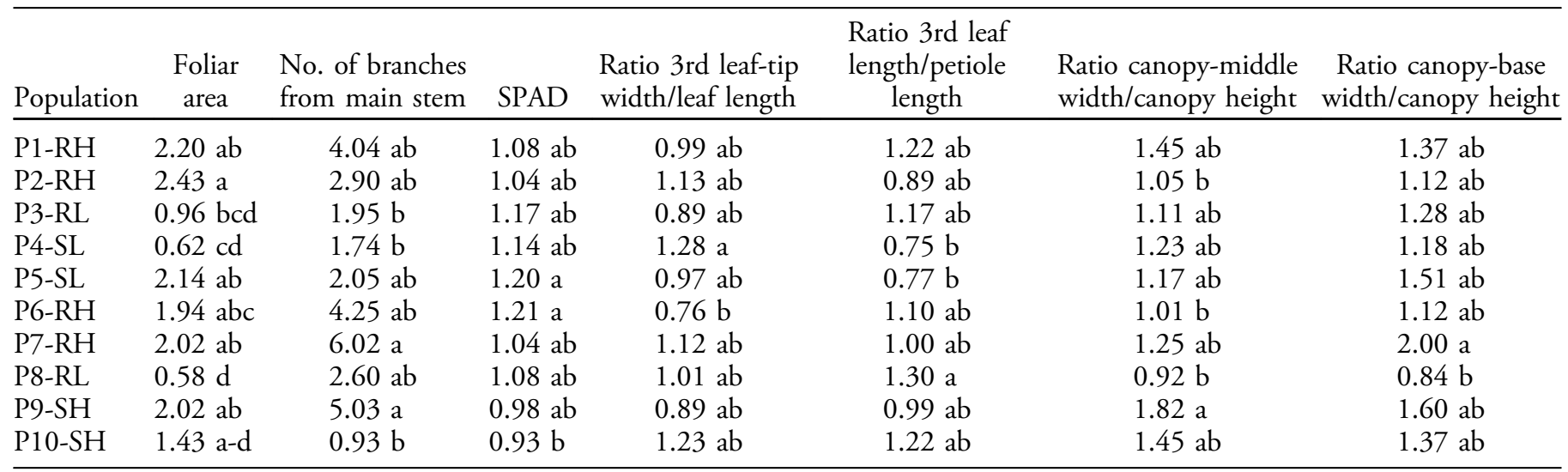

${ }^{a}$ Means within a column followed by the same letter are not different according to Tukey's honestly significant difference $(\alpha=0.05)$. Values represent the pooled means of two independent experiments $(n=12)$.

maintaining lower nitrogen, phosphorus, and magnesium content than GS populations (Table 7) without sacrificing growth.

Our results showed that populations collected from systems with high nitrogen-fertilization histories have adapted to take advantage of increased nitrogen availability provided by fertilizer inputs, changing their morphology by allocating resources to the production of branches, foliar area, reproductive tissue, and wider leaves, and ultimately increasing NUE. However, since no single population exhibited consistent changes across all evaluated traits in response to nitrogen fertilization, we think that a combination of cropping-system characteristics and not only nitrogen-input history are responsible for the differences observed among populations. Nitrogen fertilization can also modify crop-weed interactions (Blackshaw and Brandt 2008), so the response of the crop and the structure of the weed community could have influenced the importance of nitrogenfertilization history on Palmer amaranth populations. Harbur and Owen (2004) found that nitrogen
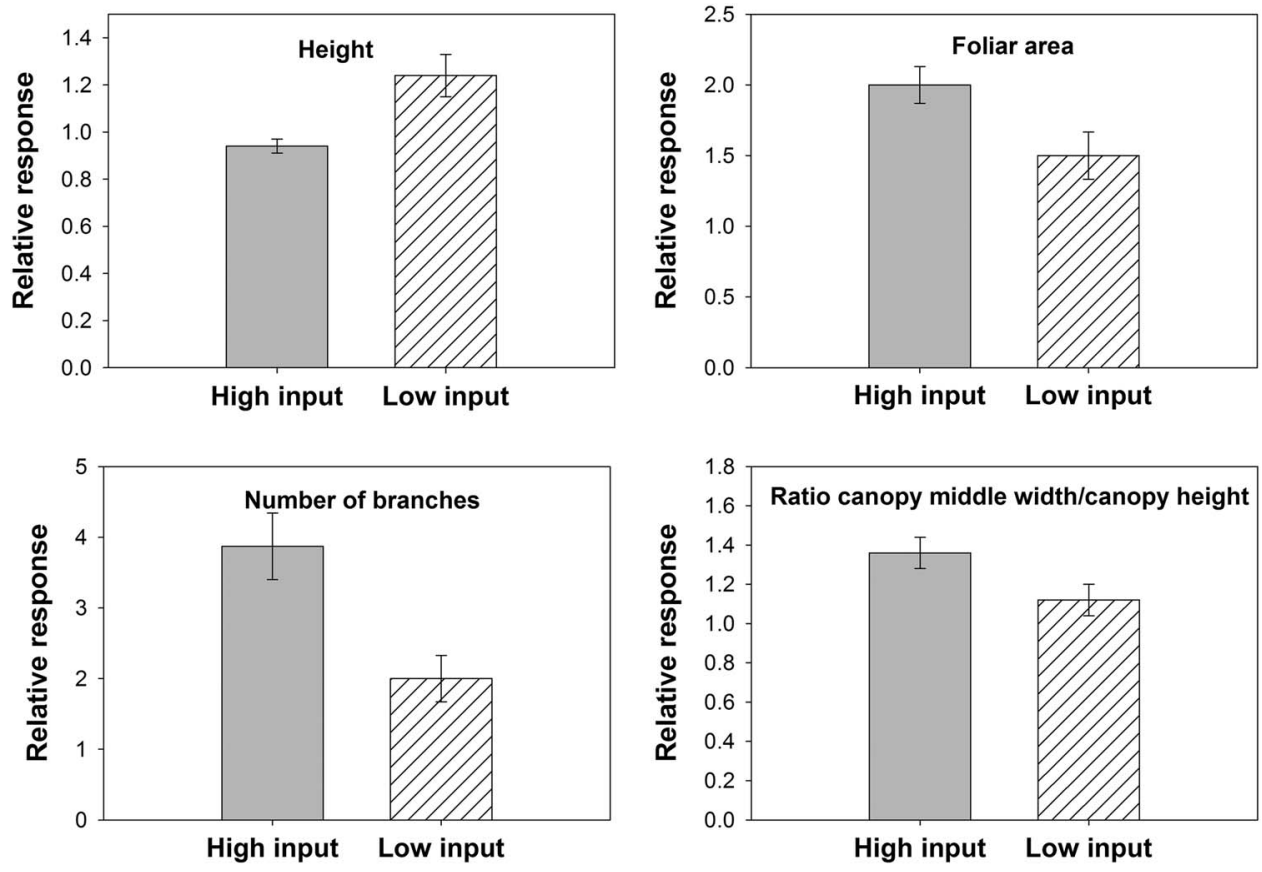

Figure 1. Relative change in morphological traits in response to nitrogen fertilization based on a nonfertilized control for Palmer amaranth populations with high and low nitrogen-fertilization histories. Six populations came from cropping systems with high nitrogen-fertilization histories $(n=72)$ and four from low nitrogen-fertilization histories $(n=48)$. Error bars represent $95 \%$ confidence intervals. 

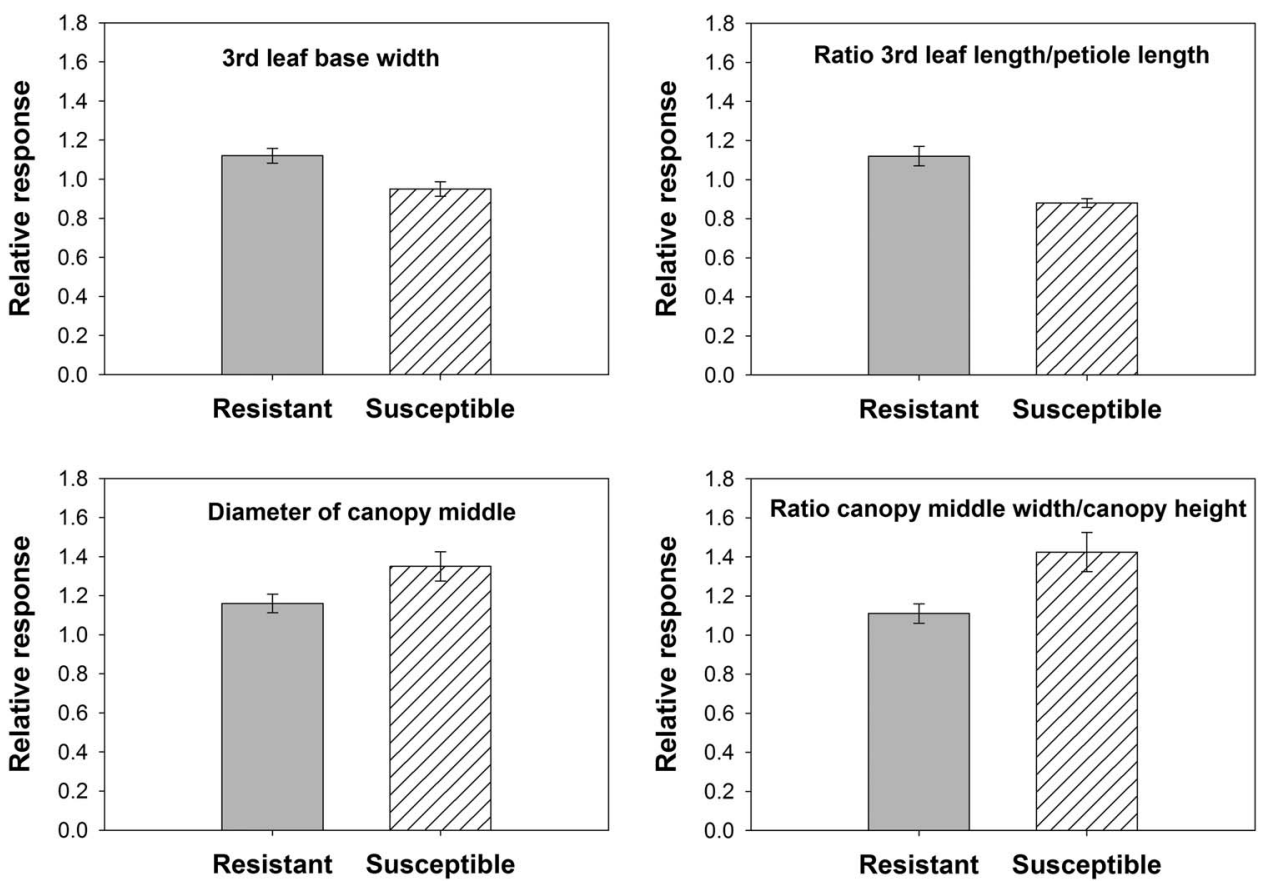

Figure 2. Relative change in morphological traits in response to nitrogen fertilization based on a nonfertilized control for glyphosateresistant (GR) and glyphosate-susceptible (GS) Palmer amaranth populations. Six populations were identified as GR ( $n=72)$ and four as GS $(n=48)$. Error bars represent $95 \%$ confidence intervals.

response of competitive weed species is affected by photosynthetically active radiation and the maximum potential growth rate of the plant, factors that vary greatly depending on crop canopy. Therefore, it would be beneficial for Palmer amaranth plants to take advantage of nitrogen fertilization to optimize canopy structure and maximize light interception under crop competition (Barnes et al. 1990). However, the changes in canopy structure will also depend on the characteristics of the canopy of the cropping system. Bravo et al. (2017) found that crop species and canopy height explained differences in growth and morphological traits among Palmer amaranth populations. The present study underlines the

Table 4. ANOVA statistical significance of differences among 10 Palmer amaranth populations for nutrient content and nutrient-use efficiency (NUE). ${ }^{a}$

\begin{tabular}{lll}
\hline Nutrient & Nutrient content & NUE \\
\hline & \multicolumn{2}{c}{ P value } \\
\cline { 2 - 3 } Nitrogen & 0.01 & 0.003 \\
Phosphorous & 0.19 & 0.007 \\
Potassium & 0.31 & 0.003 \\
Magnesium & 0.008 & 0.004 \\
Zinc & 0.21 & 0.07 \\
\hline
\end{tabular}

${ }^{a}$ There were no interactions between population and nitrogenfertilization treatments $(\mathrm{P}>0.15)$, so data of fertilized and nonfertilized plants were pooled for the analysis. importance of fertilization as a key component of integrated weed management strategies not only to avoid favoring weeds over crops in competition interactions (Ampong-Nyarko and De Datta 1993), but also to prevent evolutionary adaptations increasing weediness.

Table 5. Nutrient use efficiency (NUE) among 10 Palmer amaranth populations.

\begin{tabular}{lllll}
\hline & \multicolumn{4}{c}{ NUE $^{\mathrm{a}}$} \\
\cline { 2 - 5 } Population & Nitrogen & Phosphorous & Potassium & Magnesium \\
\hline & \multicolumn{5}{c}{$\mathrm{g} \mathrm{mg}^{-1}$} \\
P1-RH & $0.073 \mathrm{ab}$ & $0.30 \mathrm{a}$ & $0.065 \mathrm{ab}$ & $0.12 \mathrm{a}$ \\
P2-RH & $0.092 \mathrm{a}$ & $0.36 \mathrm{a}$ & $0.081 \mathrm{a}$ & $0.12 \mathrm{a}$ \\
P3-RL & $0.081 \mathrm{ab}$ & $0.31 \mathrm{a}$ & $0.073 \mathrm{ab}$ & $0.12 \mathrm{a}$ \\
P4-SL & $0.037 \mathrm{ab}$ & $0.16 \mathrm{a}$ & $0.034 \mathrm{~b}$ & $0.05 \mathrm{a}$ \\
P5-SL & $0.036 \mathrm{~b}$ & $0.32 \mathrm{a}$ & $0.036 \mathrm{ab}$ & $0.05 \mathrm{a}$ \\
P6-RH & $0.080 \mathrm{ab}$ & $0.31 \mathrm{a}$ & $0.072 \mathrm{ab}$ & $0.12 \mathrm{a}$ \\
P7-RH & $0.073 \mathrm{ab}$ & $0.30 \mathrm{a}$ & $0.063 \mathrm{ab}$ & $0.10 \mathrm{a}$ \\
P8-RL & $0.044 \mathrm{ab}$ & $0.19 \mathrm{a}$ & $0.045 \mathrm{ab}$ & $0.07 \mathrm{a}$ \\
P9-SH & $0.073 \mathrm{ab}$ & $0.28 \mathrm{a}$ & $0.066 \mathrm{ab}$ & $0.13 \mathrm{a}$ \\
P10-SH & $0.042 \mathrm{ab}$ & $0.15 \mathrm{a}$ & $0.036 \mathrm{ab}$ & $0.06 \mathrm{a}$
\end{tabular}

${ }^{a}$ Means within a column followed by the same letter are not different according to Tukey's honestly significant difference $(\alpha=0.05)$. Values represent the pooled means of two independent experiments $(n=24)$. There were no interactions between population and nitrogen-fertilization treatments for NUE $(\mathrm{P}>0.15)$, so data of fertilized and nonfertilized plants were pooled for the analysis. 
Table 6. Nutrient use efficiency (NUE) among Palmer amaranth populations with a history of high and low nitrogen fertilization.

\begin{tabular}{lccc}
\hline & \multicolumn{2}{c}{ Nitrogen-fertilization history $^{\mathrm{a}}$} & \\
\cline { 2 - 3 } Nutrient & High & Low & Comparison \\
\cline { 2 - 3 } & \multicolumn{2}{c}{$\mathrm{NUE}\left(\mathrm{g} \mathrm{mg}^{-1}\right)$} & P value \\
Nitrogen & 0.076 & 0.053 & $<0.001$ \\
Phosphorous & 0.316 & 0.208 & $<0.001$ \\
Potassium & 0.071 & 0.048 & 0.001 \\
Magnesium & 0.118 & 0.082 & 0.006 \\
Zinc & 36.3 & 22.8 & 0.003 \\
\hline
\end{tabular}

${ }^{a}$ Populations were classified according to nitrogen-fertilization history with high and low receiving an average over $8 \mathrm{yr}$ of $>90$ and $<45 \mathrm{~kg} \mathrm{~N} \mathrm{ha}^{-1} \mathrm{yr}^{-1}$, respectively.

${ }^{\mathrm{b}}$ Within rows and response trait, $\mathrm{P}$ values compare high- and low-nitrogen history groups based on a one-tailed $t$-test $(\alpha=0.05)$. Six populations (24 replications per each population) were identified as high $(n=144)$ and four as low $(n=96)$. There were no interactions between nitrogen history and nitrogenfertilization treatments for NUE ( $>>0.15)$, so data of fertilized and nonfertilized plants were pooled for the analysis.

Morphological differences related to herbicide resistance have been previously reported for other weed species (Hall and Romano 1995; Kumar and Jha 2016), which in the case of Palmer amaranth populations indicate a possible competitive advantage for GR individuals. Since resistant individuals can survive herbicide applications, competition with the crop becomes an important selection force. For instance, the more-elongated canopy, with branching patterns that separate leaves, reducing "selfshading," enables GR populations to maximize light interception and better compete against the crop canopy (Roig-Villanova and Martinez-Garcia 2016).

Our data suggest that the increased growth in GR Palmer amaranth populations compared with GS populations (Bravo et al. 2017) might be partially due to adaptations in metabolic processes favoring higher NUE. These adaptations could have occurred before or after GR trait evolution and spread, and the explanation of why the GR and NUE traits seem to be related in the present study remains elusive. Although previous studies have suggested no fitness differences between GR and GS Palmer amaranth populations (Chandi et al. 2013a; Giacomini et al. 2014; Vila-Aiub et al. 2014), the clear differences in growth reported by Bravo et al. (2017) indicate that GR populations might be capable of evolving greater growth potential than GS populations depending on selection pressures exerted by the cropping system and its production practices.

Once resistance is confirmed, researchers explore the possibility that the resistant trait also causes fitness penalties (Chandi et al. 2013a; Giacomini et al. 2014). These are efforts that have a physiological goal, which is to determine whether the mutation has pleotropic effects on the growth of the plant. It is frequently proposed that if the mutation has a fitness penalty, stopping the use of the herbicide in question eliminates the advantage that herbicide-resistant individuals have, which ultimately will allow susceptible individuals (without the fitness penalty) to become predominant again (Diggle et al. 2003; Gressel and Segel 1978). Unless the fitness penalty is extremely severe, it is possible that through the appearance of mutations or gene flow via cross-pollination, individuals carrying the herbicide-resistance trait and suffering the fitness penalty associated with it can acquire modifications in metabolism that might be able to compensate for the aforementioned penalty. Although there is no fitness penalty associated with glyphosate resistance, the present study provides evidence of this last scenario by documenting what seems to be a gain

Table 7. Nutrient content and nutrient-use efficiency (NUE) among glyphosate-resistant (GR) and glyphosate-susceptible (GS) Palmer amaranth populations. ${ }^{\text {a }}$

\begin{tabular}{|c|c|c|c|c|c|c|}
\hline \multirow[b]{2}{*}{ Nutrient } & \multicolumn{2}{|c|}{ Nutrient content } & \multirow[b]{2}{*}{ Comparison } & \multicolumn{2}{|c|}{ NUE } & \multirow[b]{2}{*}{ Comparison } \\
\hline & GR & GS & & GR & GS & \\
\hline & & & $P$ value & & & $P$ value \\
\hline Nitrogen & 23.8 & 25.9 & 0.03 & $0.073^{\circ}$ & 0.048 & 0.001 \\
\hline Phosphorous & 5.70 & 6.27 & 0.005 & 0.293 & 0.188 & 0.001 \\
\hline Potassium & 23.4 & 26.5 & 0.17 & 0.066 & 0.044 & 0.001 \\
\hline Magnesium & 15.3 & 17.4 & 0.001 & 0.110 & 0.075 & 0.007 \\
\hline Zinc & 0.75 & 0.73 & 0.84 & 33.3 & 20.2 & 0.005 \\
\hline
\end{tabular}

${ }^{a}$ Within rows and response trait, P values compare resistant and susceptible groups based on a one-tailed $t$-test $(\alpha=0.05)$. Six populations (24 replications per each population) were identified as GR $(n=144)$ and four as GS $(n=96)$. There were no interactions between glyphosate sensitivity and nitrogen-fertilization treatments $(\mathrm{P}>0.32)$, so data of fertilized and nonfertilized plants were pooled for the analysis. 
in fitness. The fact that GR populations had bigger individuals than GS populations (Bravo et al. 2017) and that GR populations were able to evolve higher NUE than GS populations clearly indicates that genetic changes in the metabolism of the plant can mitigate for fitness penalties associated with herbicide resistance and even increase the fitness of resistant populations. GR populations collected in Georgia came from areas where EPSPS gene amplification was confirmed (Culpepper et al. 2006; Gaines et al. 2010), and Florida GR populations are thought to have been introduced from Georgia. It is possible that the mechanism of gene amplification created genetic variability favoring adaptation. In fact, Molin et al. (2017) described changes in genomic content and structure in Palmer amaranth genome regions containing EPSPS gene amplification (i.e., EPSPS cassette). Some of the putative genes flanking the EPSPS cassette had functions related to stress responses and DNA replication and mobility. Furthermore, GR populations in the southeastern United States have been reported having multiple resistance, especially to ALS-inhibiting herbicides (Berger et al. 2015), so selection forces affecting adaptive traits could have influenced GR populations even when herbicides with other mechanisms of action were used. Although understanding secondary effects of herbicide-resistance traits is important, we must not ignore the fact that evolutionary adaptations might occur rapidly in agroecosystems, and weeds might be able to evolve compensatory mechanisms to disadvantages generated when herbicide resistance first evolves. Darmency et al. (2015) documented differences in the genetic background of a resistant biotype carrying a Gly-2078 mutation compared with other mutations conferring resistance to acetyl-coenzyme A-carboxylase-inhibiting herbicides in blackgrass (Alopecurus myosuroides Huds.). These researchers proposed that rapid evolution in the genetic background of the Gly-2078 biotype allowed the plant to compensate for the fitness penalty associated with this mutation. Therefore, to properly assess the impact of a herbicide-resistance trait on the fitness of a weed, it is important to assess genetic diversity within and across populations and the ecological context in which those populations exist.

It is not clear why previous studies did not find differences in fitness between GR and GS biotypes, but it is possible that those studies used Palmer amaranth from similar cropping systems (although this is not specified in the articles). Another possibility is that seed collection in those studies was done when glyphosate resistance was just starting, and our study is identifying adaptations in other life-history traits that occurred later. If this is the case, Palmer amaranth exhibits rapid evolution under selection pressure in row-crop systems.

Conclusions. The results of the present study partially confirmed our hypotheses that nitrogenfertilization history has modified Palmer amaranth populations' growth and NUE, and that GR Palmer amaranth populations can produce more biomass than GS populations in response to nitrogen fertilization. However, our study also suggests that a combination of selection forces specific to each cropping system might be responsible for differentiation among Palmer amaranth populations in response to nitrogen fertilization. Additionally, GR populations seem to have either coevolved or acquired higher NUE, which could partially explain the increased growth reported by Bravo et al. (2017) in GR compared with GS populations. These results highlight the need to study the competitive interactions of Palmer amaranth in different cropping systems in more detail, incorporating evolutionary considerations, since selection forces such as nitrogen availability and herbicide resistance might be interacting and increasing the weediness and success of this aggressive weed species in multiple cropping systems.

\section{Acknowledgments}

We thank Ted Webster, Carroll Johnson, Tim Grey, Josh Thompson, and William Starr for helpful guidance and assistance during seed collection. We also thank Sharon Howell, Michael Dozier, and Rocio van der Laat for technical support. This research was partially funded by the Institute of Food and Agricultural Sciences, University of Florida.

\section{Literature Cited}

Ampong-Nyarko K, De Datta SK (1993) Effects of nitrogen application on growth, nitrogen use efficiency and rice-weed interaction. Weed Res 33:269-276

Barnes PW, Flint SD, Caldwell MM (1990) Morphological responses of crop and weed species of different growth forms to ultraviolet-B radiation. Am J Bot 77:1354-1360

Berger ST, Ferrell JA, Dittmar PT, Leon R (2015) Survey of glyphosate- and imazapic-resistant Palmer amaranth (Amaranthus palmeri) in Florida. Crop Forage Turf Manag 1:1

Blackshaw RE, Brandt RN (2008) Nitrogen fertilizer rate effects on weed competitiveness is species dependent. Weed Sci 56:743-747

Bravo WB, Leon RG, Ferrell JA, Mulvaney MJ, Wood CW (2017) Differentiation of life-history traits among Palmer amaranth populations (Amaranthus palmeri) and its relation to cropping systems and glyphosate sensitivity. Weed Sci 65:339-349

Butts TR, Norsworthy JK, Kruger GR, Sandell LD, Young BG, Steckel LE, Loux MM, Bradley KW, Conley SP, Stoltenberg

188 • Weed Science 66, March-April 2018 
DE, Arrriaga FJ (2016) Management of pigweed (Amaranthus spp.) in glufosinate-resistant soybean in the Midwest and mid-South. Weed Technol 30:355-365

Cassman KG, Peng S, Olk DC, Ladha JK, Reichardt W, Dobermann A, Singh U (1998) Opportunities for increased nitrogen-use efficiency from improved resource management in irrigated rice systems. Field Crop Res 56:7-39

Chandi A, Jordan DL, York AC, Milla-Lewis SR, Burton JD, Culpepper AS, Whitaker JR (2013a) Interference and control of glyphosate-resistant and -susceptible Palmer amaranth (Amaranthus palmeri) populations under greenhouse conditions. Weed Sci 61:259-266

Chandi A, Milla-Lewis SR, Jordan DL, Burton JD, Zuleta MC, Whitaker JR, Culpepper AS (2013b) Use of AFLP markers to assess genetic diversity in Palmer amaranth (Amaranthus palmeri) populations from North Carolina and Georgia. Weed Sci 61:136-145

Culpepper AS, Grey TL, Vencill WK, Kichler JM, Webster TM, Brown SM, York AC, Davis JW, Hanna WW (2006) Glyphosate-resistant Palmer amaranth (Amaranthus palmeri) confirmed in Georgia. Weed Sci 54:620-626

Darmency H, Menchari Y, Le Corre V, Délye C (2015) Fitness cost due to herbicide resistance may trigger genetic background evolution. Evolution 69:271-278

De Datta SK, Broadbent FE (1988) Methodology for evaluating nitrogen-utilization efficiency by rice genotypes. Agron J 80:793-798

Diggle AJ, Neve PB, Smith FP (2003) Herbicides used in combination can reduce the probability of herbicide resistance in finite weed populations. Weed Res 43:371-382

[EPA] Environmental Protection Agency (1993) Method 351.2, Revision 2.0: Determination of Total Kjeldahl Nitrogen by Semi-automated Colorimetry. https://www.epa.gov/sites/ production/files/2015-08/documents/method_351-2_1993.pdf. Accessed: March 15, 2015

[EPA] Environmental Protection Agency (1994) Method 200.7, Revision 4.4: Determination of Metals and Trace Elements in Water and Wastes by Inductively Coupled Plasma-Atomic Emission Spectrometry. https://www.epa.gov/sites/production/ files/2015-08/documents/method_200-7_rev_4-4_1994.pdf. Accessed: March 15, 2015

Gaeddert JW, Peterson DE, Horak MJ (1997) Control and crossresistance of an acetolactate synthase inhibitor-resistant Palmer amaranth (Amaranthus palmeri) biotype. Weed Technol 11:132-137

Gaines TA, Zhang W, Wang D, Bukun B, Chisholm ST, Shaner DL, Nissen SJ, Patzoldt WL, Tranel PJ, Culpepper AS, Grey TL (2010) Gene amplification confers glyphosate resistance in Amaranthus palmeri. Proc Natl Acad Sci USA 107:1029-1034

Giacomini D, Westra P, Ward SM (2014) Impact of genetic background in fitness cost studies: an example from glyphosate-resistant Palmer amaranth. Weed Sci 62:29-37

Gossett BJ, Murdock EC, Toler JE (1992) Resistance of Palmer amaranth (Amaranthus palmeri) to the dinitroaniline herbicides. Weed Technol 6:587-591

Gressel J, Segel LA (1978) The paucity of plants evolving genetic resistance to herbicides: possible reasons and implications. J Theor Biol 75:349-371

Hall JC, Romano ML (1995) Morphological and physiological differences between the auxinic herbicide-susceptible $(S)$ and herbicide-resistant (R) wild mustard (Sinapis arvensis L) biotypes. Pest Biochem Physiol 52:149-155
Harbur MM, Owen MD (2004) Light and growth rate effects on crop and weed responses to nitrogen. Weed Sci 52:578-583

Heap I (2017) The International Survey of Herbicide Resistant Weeds. http://weedscience.org/graphs/speciesbysoacount.aspx. Accessed: April 1, 2016

Jhala AJ, Sandell LD, Rana N, Kruger GR, Knezevic SZ (2014) Confirmation and control of triazine and 4-hydroxyphenylpyruvate dioxygenase-inhibiting herbicide-resistant Palmer amaranth (Amaranthus palmeri) in Nebraska. Weed Technol 28:28-38

Kumar V, Jha P (2016) Differences in germination, growth, and fecundity characteristics of dicamba-fluroxypyr-resistant and susceptible Kochia scoparia. PLoS ONE 11(8): e0161533

Mohseni-Moghadam M, Schroeder J, Ashigh J (2013) Mechanism of resistance and inheritance in glyphosate resistant Palmer amaranth (Amaranthus palmeri) populations from New Mexico, USA. Weed Sci 61:517-525

Molin WT, Wright AA, Lawton-Rauh A, Saski CA (2017) The unique genome landscape surrounding the EPSPS gene in glyphosate resistant Amaranthus palmeri: a repetitive path to resistance. BMC Genomics 18:91

Norsworthy JK, Griffith GM, Scott RC, Smith KL, Oliver LR (2008) Confirmation and control of glyphosate-resistant Palmer amaranth (Amaranthus palmeri) in Arkansas. Weed Technol 22:108-113

R Core Team (2014) R: A language and Environment for Statistical Computing. Vienna, Austria: R Foundation for Statistical Computing. http://www.R-project.org

Roig-Villanova I, Martinez-Garcia JF (2016) Plant response to vegetation proximity: a whole life avoiding shade. Front Plant Sci 7:236

Ruf-Pachta EK, Rule DM, Dille JA (2013) Corn and Palmer amaranth (Amaranthus palmeri) interactions with nitrogen in dryland and irrigated environments. Weed Sci 61:249-258

Sweeney AE, Renner KA, Laboski C, Davis A (2008) Effect of fertilizer nitrogen on weed emergence and growth. Weed Sci 56:714-721

Vila-Aiub MM, Goh SS, Gaines TA, Han H, Busi R, Yu Q, Powles SB (2014) No fitness cost of glyphosate resistance endowed by massive EPSPS gene amplification in Amaranthus palmeri. Planta 239:793-801

Ward SM, Webster TM, Steckel LE (2013) Palmer amaranth (Amaranthus palmeri): a review. Weed Technol 27:12-27

Webster TM, Coble HD (1997) Changes in the weed species composition of the southern United States: 1974 to 1995. Weed Technol 11:308-317

Wiggins MS, McClure MA, Hayes RM, Steckel LE (2015) Integrating cover crops and POST herbicides for glyphosateresistant Palmer amaranth (Amaranthus palmeri) control in corn. Weed Technol 29:412-418

Wood CW, Reeves DW, Duffield RR, Edmisten KL (1992) Field chlorophyll measurements for evaluation of corn nitrogen status. J Plant Nutr 15:487-500

Wortman SE, Davis AS, Schutte BJ, Lindquist JL (2011) Integrating management of soil nitrogen and weeds. Weed Sci 59:162-170

Received September 19, 2017, and approved November 6, 2017.

Associate Editor for this paper: Timothy L. Grey, University of Georgia.

Bravo et al.: Palmer amaranth fertilization adaptation • 